\title{
Menstrual Problems in Undergraduate Medical Students: A Cross-sectional Study in a Medical College of North India
}

\author{
Verma Indu ${ }^{1}$, Joshi Gaurika ${ }^{2}$, Sood Dinesh ${ }^{3}$, Soni RK ${ }^{4}$
}

\begin{abstract}
Introduction: Regular menstruation symbolizes a normal reproductive health of woman; however, virtually all women experience some form of menstrual problem in their lifetime. Medical undergraduates are mostly in the age group of late adolescence and early twenties. Females in this age group frequently experience different menstrual problems that commonly affect their quality of life. These disorders may be so severe that they influence the routine physical activity of the girls and also force them to skip their classes.

Aim: This study was done to determine the menstrual pattern, menstrual problems, and associated factors among undergraduate medical students.

Materials and methods: This college-based cross-sectional prospective study was conducted on 183 unmarried undergraduate female medical students. They were asked to fill and return a semi-structured self-explanatory questionnaire prepared in English containing details of sociodemography, menstrual history and menstrual problems, diet, and exercise.

Results: Mean age of menarche was $13.37 \pm 1.40$ years, and most of them were residing in the hostel. Premenstrual syndrome (PMS) was the most common menstrual problem faced by the students (85.24\%), and mood swing being the commonest symptom noted in 132 participants. Dysmenorrhea was seen in $111(60.66 \%)$ out of which 68 needed some form of medication and 12 reported absenteeism from the college. An abnormal bleeding pattern was reported by 89 (48.63\%). In our study, $73.22 \%$ students were doing regular exercise and $71.04 \%$ were consuming unhealthy diet. Students doing regular exercise had less prevalence of dysmenorrhea, which was statistically significant $(p=0.032)$. Dysmenorrhea was significantly associated with PMS $(p=0.022)$ and severity of PMS $(p=0.001)$. There was no significant association of dysmenorrhea with the menstrual cycle pattern, BMI, or food. No significant association of PMS or its severity was noted with menstrual cycle, BMI, food, or exercise. Oligomenorrhea was significantly associated with normal BMI $(p=0.019)$.

Conclusion: The commonest menstrual problem seen in our study was PMS. The psychological symptoms of PMS were more as compared to physical symptoms. Some form of medication was required in $61.26 \%$ of dysmenorrhic students. A strong association was seen between dysmenorrhea and exercise; students exercising regularly had low incidence of dysmenorrhea. Since there is a high prevalence of menstrual problems in medical students, so these issues need to be addressed timely along with counseling and appropriate treatment.

Keywords: Body mass index, Dysmenorrhea, Medical students, Premenstrual syndrome.

Journal of South Asian Federation of Obstetrics and Gynaecology (2020): 10.5005/jp-journals-10006-1774
\end{abstract}

\section{INTRODUCTION}

Menstruation is the visible manifestation of cyclic physiologic uterine bleeding due to shedding of the endometrium following invisible interplay of hormones mainly through the hypothalamopituitaryovarian axis. ${ }^{1}$ All women experience some or other form of menstrual problem [excessive uterine bleeding, dysmenorrhea, and premenstrual syndrome (PMS)] in their lifetime, most prevalent in adolescence and early twenties.

Menstrual pattern abnormalities can be amenorrhea, oligomenorrhea, polymenorrhea, metrorrhagia, menorrhagia, and hypermenorrhea. Dysmenorrhea is cramping pain with menstruation, centered in the lower abdomen with incidence of $53.8-89.7 \%$ in medical/nursing students. ${ }^{2-6}$ Premenstrual syndrome is a cyclic physical and behavioral symptom, appearing in days preceding menses and interferes with work or lifestyle, followed by a symptom-free interval. Most common PMS physical symptoms include abdominal bloating, extreme fatigue, breast tenderness, and headaches, all occurring in $50-90 \%$ of cases and behavioral symptoms are mood liability, irritability, depressed mood, increased appetite, forgetfulness, and difficulty with concentration, occurring in $50-80 \%$ of cases. Premenstrual symptoms are very common, reported by up to $75 \%$ of woman with regular menstrual cycles. ${ }^{7}$ Reported incidence of PMS in medical/nursing students is
${ }^{1}$ Department of Obstetrics and Gynecology, Christian Medical College and Hospital, Ludhiana, Punjab, India

${ }^{2}$ Department of Obstetrics and Gynecology, Maharishi Markandeshwar Institute of Medical Sciences and Research, Mullana, Ambala, Haryana, India

${ }^{3}$ Department of Anaesthesia, Dayanand Medical College and Hospital, Ludhiana, Punjab, India

${ }^{4}$ Department of PSM, Dayanand Medical College and Hospital, Ludhiana, Punjab, India

Corresponding Author: Indu Verma, Department of Obstetrics and Gynecology, Christian Medical College and Hospital, Ludhiana, Punjab, India, Phone: +91 9814046817, e-mail: drinduverma68@gmail.com

How to cite this article: Indu V, Gaurika J, Dinesh S, et al. Menstrual Problems in Undergraduate Medical Students: A Cross-sectional Study in a Medical College of North India. J South Asian Feder Obst Gynae 2020;12(2):85-90.

Source of support: Nil

Conflict of interest: None

46.7-69\%. ${ }^{2,4-6}$ Stressed lifestyle, irregular food habits, and lack of exercise in medical students make them vulnerable for menstrual abnormalities. ${ }^{6,8}$ Dysmenorrhea and PMS are the commonest 
grounds of absenteeism from class/college, limiting social, academic, sports, and daily activities. ${ }^{2,4}$ Authors have reported that most of the menstrual problems can be prevented by early detection and suitable treatment. ${ }^{4,9}$

\section{Materials and Methods}

After approval from the institutional ethics committee, 200 unmarried undergraduate female medical students consented and willingly participated in the study. They were explained the purpose of the study and requested to anonymously fill a predesigned semi-structured self-explanatory questionnaire prepared in English once only and return it to the second author (participant and student of same college) within 1 week's time. The questionnaire provided data related to their sociodemographic and obstetric/gynecologic information. It contained questions related to anthropometric details, history of excess of facial or body hair and acne, menstrual history including age of menarche, average length of cycle and duration of bleeding during last 6 months, regularity of the cycle, and number and type of pads used per day. Girls were asked to report about menstrual abnormalities like presence of dysmenorrhea that was graded as: able to do routine activities (mild), relieved by medication (moderate), and absence from the class (severe). Presence or absence of menorrhagia, hypomenorrhea, oligomenorrhea, and amenorrhea; increased vaginal discharge; or a vulval rash in the premenstrual period were also noted. Occurrence of mood swing, breast tenderness, edema, food craving, headache, migraine, and depression were diagnostic of PMS (presence of one to two symptoms: mild, three to four: moderate, and five to seven: severe PMS). Number of students who skipped classes and needed medication for some menstrual abnormality and its type were also noted. Healthy diet history of students included salad, fruit, milk, egg, and protein-rich food. It was labeled as regular healthy diet when they consumed two to three of these items for four to five times/week or occasional when the frequency of intake was less. Unhealthy diet included fast food, beverages, and sweets if taken regularly (four to five times per week). Details were noted about the exercise pattern in the form of walking, exercising in the gym, dance, yoga, or participation in any sports activity for 30-40 minutes. Having done any of the physical activity more than or equal to four to five times/week was considered doing regular physical activity and those indulging one to three times/week were considered doing occasional physical activity.

\section{Results}

Out of 200 unmarried, female medical undergraduates, aged 17-28 years, only 183 returned the completely filled proforma with the response rate of $91.5 \%$. All the girls belonged to the upper (39.34\%) or upper middle $(60.66 \%)$ class of the socioeconomic status and $96.2 \%$ were residing in the hostels. One hundred and sixty-two $(88.5 \%)$ belonged to the urban background whereas rest were from the rural areas. Mean body mass index (BMI) was $22.88 \pm 3.4$ $\mathrm{kg} / \mathrm{m}^{2}$ and most of them (59.01\%) had normal, whereas $29.51 \%$ had higher and $11.48 \%$ lower than normal BMI. One hundred and fifteen (62.8\%) girls were vegetarian and 134 (73.2\%) were doing regular exercise (Table 1). Menstrual details, number and type of pads used, and frequency of PMS symptoms present are shown in Table 2. Dysmenorrhea was seen in 111 (60.66\%) girls and out of 111 dysmenorrhic girls, 56 (50.45\%) girls needed some form of medication. Severe dysmenorrhea was the cause of absence
Table 1: Sociodemographic, physical, diet, and exercise details

\begin{tabular}{|c|c|}
\hline Variables & Mean $\pm S D$ (range) \\
\hline Age (years) & $20.97 \pm 1.43(17-28)$ \\
\hline Height (cm) & $161.76 \pm 6.39(149-180)$ \\
\hline Weight (kg) & $60.28 \pm 10.39(40-90)$ \\
\hline \multicolumn{2}{|l|}{$\operatorname{SES}(n=183)$} \\
\hline Upper & 72 (39.34\%) \\
\hline Upper middle & $111(60.66 \%)$ \\
\hline \multicolumn{2}{|l|}{ Stay $(n=183)$} \\
\hline Hostel & $176(96.2 \%)$ \\
\hline Day scholar & $7(3.8 \%)$ \\
\hline \multicolumn{2}{|l|}{ Residence $(n=183)$} \\
\hline Rural & $21(11.5 \%)$ \\
\hline Urban & $162(88.5 \%)$ \\
\hline BMI mean $\left(\mathrm{kg} / \mathrm{m}^{2}\right)$ & $22.88 \pm 3.54(16.7-34)$ \\
\hline \multicolumn{2}{|l|}{$\operatorname{BMI}\left(\mathrm{kg} / \mathrm{m}^{2}\right)(n=183)$} \\
\hline Normal (18.5-24.9) & $108(59.01 \%)$ \\
\hline High $(>24.9)$ & $54(29.50 \%)$ \\
\hline Low $(<18.5)$ & $21(11.48 \%)$ \\
\hline \multicolumn{2}{|l|}{ Presence of } \\
\hline Excess body/facial hair & $32(17.5 \%)$ \\
\hline Acne & $43(23.5 \%)$ \\
\hline \multicolumn{2}{|l|}{$\operatorname{Diet}(n=183)$} \\
\hline Vegetarian & $115(62.8 \%)$ \\
\hline Nonvegetarian & $68(37.2 \%)$ \\
\hline Exercise $(n=183)$ & Regular $(n=134)$ \\
\hline Walk & $124(67.76 \%)$ \\
\hline Gym & $36(19.67 \%)$ \\
\hline Dance & $19(10.38 \%)$ \\
\hline Yoga & $21(11.48 \%)$ \\
\hline Sports & $7(3.82 \%)$ \\
\hline
\end{tabular}

from class in $12(6.56 \%)$ students. Menorrhagia was seen in 34 (18.58\%), hypermenorrhea in 12 (6.56\%), oligomenorrhea in 27 (14.75\%), amenorrhea in 7 (3.83\%), and metrorhagia in 5 (2.73\%) of the participants. Increased pre-/postmenstrual discharge in 41 and vulval rash in 27 girls were seen. Frequency of PMS symptoms present in the girls is depicted in Table 2. History of intake of some hormonal preparations was seen in $13(7.1 \%)$ girls. Past history of some form of injury was noted in 7 (3.38\%) and family history of menstrual problems was present in 15 (8.2\%) participants. Association of dysmenorrhea, menstrual cycle, BMI, food, exercise, PMS, and PMS severity with each other is shown in Tables 3 to 5 . Table 6 shows association of BMI with menorrhagia and oligomenorrhea.

\section{Discussion}

Menstruation is an indicator of normal reproductive/sexual health of a woman and deviation from normal is common. Abnormalities of menstruation may affect physical, physiological, or psychological well-being of the girls, more so in medical profession who are staying away from their homes in hostels, experiencing changed eating pattern, daily routine, and stress of studies. ${ }^{10}$

In our study, 183 girls returned filled proforma with a response rate of $91.5 \%$, mean age of $20.97 \pm 1.43$ years, normal BMI in 108 
Table 2: Menstrual details (menstrual cycle and abnormalities)

\begin{tabular}{|c|c|}
\hline Age of menarche (years \pm SD) & $\begin{array}{l}13.37 \pm 1.40 \\
n(\%)\end{array}$ \\
\hline \multicolumn{2}{|l|}{ Menstrual cycle (days) } \\
\hline $24-35$ & $149(81.43)$ \\
\hline$<24$ & $4(2.19)$ \\
\hline$>35$ & $34(18.57)$ \\
\hline \multicolumn{2}{|l|}{ Menstrual cycle } \\
\hline Regular & $162(88.52)$ \\
\hline Irregular & $21(11.48)$ \\
\hline \multicolumn{2}{|l|}{ Menstruation duration (days) } \\
\hline $1-2$ & $14(7.65)$ \\
\hline $3-7$ & $135(73.78)$ \\
\hline$>7$ & $34(18.57)$ \\
\hline \multicolumn{2}{|l|}{ Number of pads/day } \\
\hline $1-2$ & $12(6.56)$ \\
\hline $3-5$ & $158(86.34)$ \\
\hline$>5$ & $13(7.10)$ \\
\hline \multicolumn{2}{|l|}{ Type of pads } \\
\hline Commercial & $152(83.06)$ \\
\hline Cotton & $25(13.66)$ \\
\hline Tampon & $6(3.28)$ \\
\hline \multicolumn{2}{|l|}{ Dysmenorrhea (present $n=111$ ) } \\
\hline Mild (able to do routine activities) & $43(38.74)$ \\
\hline Moderate (required some medication) & $56(50.45)$ \\
\hline Severe (absence from class + medication) & $12(10.81)$ \\
\hline \multicolumn{2}{|l|}{ Menstrual bleeding abnormalities $(n=89)$} \\
\hline Menorrhagia & $34(18.58)$ \\
\hline Polymenorrhea & 4 (2.19) \\
\hline Hypomenorrhea & $12(6.56)$ \\
\hline Oligomenorrhea & $27(14.75)$ \\
\hline Amenorrhea (>3 months) & $7(3.83)$ \\
\hline Metrorhagia & $5(2.73)$ \\
\hline Increase pre- or postmenstrual discharge & $41(22.40)$ \\
\hline Vulval rash & $27(14.75)$ \\
\hline \multicolumn{2}{|l|}{ PMS symptoms present $\left(n=156^{*}\right)$} \\
\hline Mood swings & $132(72.13)$ \\
\hline Breast tenderness & $62(33.88)$ \\
\hline Edema & $22(12.02)$ \\
\hline Food craving & $115(62.84)$ \\
\hline Headache & $60(32.79)$ \\
\hline Migraine & $23(12.57)$ \\
\hline Depression & $58(31.69)$ \\
\hline
\end{tabular}

*Multiple symptoms may be present

(58.01\%), high BMI in 54 (29.5\%), mean age of menarche $13.37 \pm$ 1.40 years, normal menstrual cycle length in 166 (90.74\%), long in 16 , and short in 1. Regular cycles were seen in $162(88.52 \%)$ and irregularity of the cycle was observed in 21 (11.48\%) participants. In a cross-sectional study conducted among 171 female students, Karki and Gupta reported that the menarche age of the students was $12.95 \pm 1.08$ years, which was comparable to our observation; however, they observed that $33.3 \%$ of their students were having irregular cycles, which are more than our observation of $11.47 \%{ }^{2}$
Table 3: Association of dysmenorrhea with menstrual cycle, BMI, food, exercise, PMS, and PMS severity

\begin{tabular}{|c|c|c|c|c|}
\hline \multirow[b]{2}{*}{ Variables } & \multicolumn{2}{|c|}{ Dysmenorrhea } & \multirow[b]{2}{*}{ Chi-square } & \multirow[b]{2}{*}{$p$ value } \\
\hline & $\begin{array}{l}\text { Present } \\
(n=111)\end{array}$ & $\begin{array}{l}\text { Absent } \\
(n=72)\end{array}$ & & \\
\hline \multicolumn{5}{|l|}{ Menstrual cycle } \\
\hline $\begin{array}{l}\text { Regular } \\
(n=162)\end{array}$ & 99 (61.11) & $63(38.89)$ & 0.123 & 0.726 \\
\hline $\begin{array}{l}\text { Irregular } \\
(n=21)\end{array}$ & $12(57.14)$ & $9(42.86)$ & & \\
\hline \multicolumn{5}{|l|}{$\mathrm{BMI}$} \\
\hline $\begin{array}{l}\text { Underweight } \\
(n=21)\end{array}$ & $11(52.38)$ & $10(47.62)$ & 1.004 & 0.605 \\
\hline $\begin{array}{l}\text { Normal } \\
(n=108)\end{array}$ & 65 (60.19) & $43(39.85)$ & & \\
\hline $\begin{array}{l}\text { Overweight } \\
(n=54)\end{array}$ & $35(64.81)$ & 19 (35.19) & & \\
\hline \multicolumn{5}{|l|}{ Food } \\
\hline $\begin{array}{l}\text { Healthy } \\
(n=53)\end{array}$ & 33 (62.26) & $20(37.74)$ & 0.081 & 0.776 \\
\hline $\begin{array}{l}\text { Unhealthy } \\
(n=130)\end{array}$ & $78(60.00)$ & $52(40.00)$ & & \\
\hline \multicolumn{5}{|l|}{ Exercise } \\
\hline $\begin{array}{l}\text { Occasional } \\
(n=49)\end{array}$ & $36(73.47)$ & $13(26.53)$ & 4.604 & 0.032 \\
\hline $\begin{array}{l}\text { Regular } \\
(n=134)\end{array}$ & 75 (55.97) & $59(44.02)$ & & \\
\hline \multicolumn{5}{|l|}{ PMS } \\
\hline $\begin{array}{l}\text { Absent } \\
(n=27)\end{array}$ & $11(9.91)$ & $16(22.22)$ & 5.264 & 0.022 \\
\hline $\begin{array}{l}\text { Present } \\
(n=156)\end{array}$ & $100(90.09)$ & $56(77.78)$ & & \\
\hline \multicolumn{5}{|l|}{ PMS severity } \\
\hline Mild $(n=64)$ & $32(50.00)$ & $32(50.00)$ & 21.82 & 0.001 \\
\hline $\begin{array}{l}\text { Moderate } \\
(n=66)\end{array}$ & $43(65.15)$ & $23(34.85)$ & & \\
\hline Severe $(n=26)$ & $25(96.15)$ & $1(3.85)$ & & \\
\hline None $(n=27)$ & $11(40.74)$ & $16(59.26)$ & & \\
\hline
\end{tabular}

Figures in parentheses represent percentages; $p<0.05$ significant

The mean age of menarche seen by Aref et al. was $13.2 \pm 0.318$ years, which is similar to our findings of $13.37 \pm 1.40$ years. $^{5}$

In our study, the most common menstrual problem was PMS (85.24\%) of the participants. Dysmenorrhea was the second most common problem $(60.66 \%)$ of our students, which is the same as findings of Karanth and Liya who have seen presence of dysmenorrhea in $62.5 \%$ of female nursing students. ${ }^{11}$ Out of 111 students in our study, 50.45\% gave the history of moderate dysmenorrhea requiring medical treatment. We have seen that out of all the girls having dysmenorrhea, 12 (10.81\%) remained absent from the college suggesting severe form. As compared to our study, Karki and Gupta reported a slightly lower incidence (53.8\%) of dysmenorrhea with a significant association between it and absence from the classes in medical college students whereas Aref et al. have reported a slightly higher incidence (77\%) of dysmenorrhea with college absenteeism of $8.5 \% .^{2,5}$ Lakkawar et al. have also shown a higher incidence (29\%) of absenteeism from the classes 
due to dysmenorrhea. ${ }^{4}$ Yesuf et al. observed a higher incidence of dysmenorrhea among university health sciences students (71.8\%), with irregularity of menses in $32.6 \%$ of the girls. ${ }^{3}$ Teshome et al. studied 470 university students of Euthopia for menstrual problems

Table 4: Association of PMS with menstrual cycle, BMI, food, exercise

\begin{tabular}{|c|c|c|c|c|}
\hline \multirow[b]{2}{*}{ Variables } & \multicolumn{2}{|c|}{ PMS } & \multirow[b]{2}{*}{ Chi-square } & \multirow[b]{2}{*}{$p$ value } \\
\hline & $\begin{array}{l}\text { Present } \\
(n=156)\end{array}$ & $\begin{array}{l}\text { Absent } \\
(n=27)\end{array}$ & & \\
\hline \multicolumn{5}{|l|}{ Menstrual cycle } \\
\hline Regular $(n=162)$ & $137(84.57)$ & $25(15.43)$ & 0.516 & 0.473 \\
\hline Irregular $(n=21)$ & $19(90.48)$ & $2(9.52)$ & & \\
\hline \multicolumn{5}{|l|}{ BMI } \\
\hline $\begin{array}{l}\text { Underweight } \\
(n=21)\end{array}$ & $18(85.72)$ & $3(14.28)$ & 0.225 & 0.895 \\
\hline Normal $(n=108)$ & $91(84.26)$ & $17(15.74)$ & & \\
\hline $\begin{array}{l}\text { Overweight } \\
(n=54)\end{array}$ & $47(87.04)$ & $7(12.96)$ & & \\
\hline \multicolumn{5}{|l|}{ Diet } \\
\hline Healthy $(n=53)$ & $45(84.91)$ & $8(15.09)$ & 0.007 & 0.934 \\
\hline $\begin{array}{l}\text { Unhealthy } \\
(n=130)\end{array}$ & $111(85.38)$ & $19(14.62)$ & & \\
\hline \multicolumn{5}{|l|}{ Exercise } \\
\hline Occasional $(n=49)$ & $40(81.63)$ & $9(18.37)$ & 0.695 & 0.405 \\
\hline Regular $(n=134)$ & $116(86.57)$ & $18(13.43)$ & & \\
\hline
\end{tabular}

and factors associated with it aged 17-24 years with mean age of menarche $14.7 \pm 1.6$ years. In their study, irregular cycles were seen in $46.2 \%$ students, and dysmenorrhea was noted in $85.1 \%{ }^{12}$ An abnormal bleeding pattern was seen in $48.63 \%$ (89) of our study population while a normal bleeding pattern was observed in 94 students. Menorrhagia was the commonest abnormality seen in $34(18.58 \%)$ medical students followed by oligomenorrhea in 27 (14.75\%) students and hypomenorrhea in 12 (6.56\%), respectively. Aref et al. found that $92.5 \%$ of their students had one or more menstrual problem with an incidence of heavy bleeding in $29.9 \%$ girls. ${ }^{5}$ Symptoms of PMS were reported by $85.24 \%$ (156) of our girls whereas other authors have seen a lower incidence $46.7-69 \%^{2,4-6}$ in their study population of medical students. The commonest symptom found in our study was mood swings (84.62\%) followed by food craving (73.72\%), breast tenderness (39.74\%), and edema or bloating (12.02\%). More than two symptoms (moderate PMS) were present in 66 (42.31\%) students. A severe form of PMS (presence of five to seven symptoms) was reported by 26 (16.67\%) participants and mild (presence of only one symptom) in 64 (41.03\%) girls. Teshome et al. reported PMS in $72.8 \%$ of the girls, the commonest symptoms being irritability, fatigue, and depression. ${ }^{12}$ Rumana studied PMS in 270 medical students of a private rural medical college and found prevalence of PMS to be $31.1 \%$ with features of mild, moderate, and severe in 20,7.4, and $3.7 \%$, respectively. ${ }^{13}$ In a similar study done by Rafique and Al-Sheik on 738 female health science students in Saudi Arabia, aged 18-25 years, found a high incidence of dysmenorrhea (89.7\%), with $12.4 \%$ having severe dysmenorrhea. They also noted PMS in $46.7 \%$ and the common symptoms of PMS were mood swings, anger, irritability, and tiredness. ${ }^{6}$

Table 5: Association of PMS severity with menstrual cycle, BMI, food, exercise

\begin{tabular}{|c|c|c|c|c|c|c|}
\hline \multirow[b]{2}{*}{ Variables } & \multicolumn{4}{|c|}{ PMS severity } & \multirow[b]{2}{*}{ Chi-square } & \multirow[b]{2}{*}{$p$ value } \\
\hline & Mild & Moderate & Severe & None & & \\
\hline \multicolumn{7}{|l|}{ Menstrual cycle } \\
\hline Regular $(n=162)$ & $56(30.60)$ & $58(31.69)$ & $23(12.56)$ & $25(15.43)$ & 0.533 & 0.912 \\
\hline Irregular $(n=21)$ & 8 (38.09) & 8 (38.09) & $3(14.29)$ & $2(9.52)$ & & \\
\hline \multicolumn{7}{|l|}{ BMI } \\
\hline Underweight $(n=21)$ & $6(28.57)$ & $10(47.62)$ & $2(9.52)$ & $3(14.29)$ & 1.927 & 0.926 \\
\hline Normal $(n=108)$ & $39(36.11)$ & $37(34.26)$ & $15(13.89)$ & $17(15.74)$ & & \\
\hline Overweight $(n=54)$ & $19(35.19)$ & $19(35.19)$ & $9(16.67)$ & $7(12.96)$ & & \\
\hline \multicolumn{7}{|l|}{ Food } \\
\hline Healthy $(n=53)$ & $19(35.85)$ & $21(39.62)$ & $5(9.43)$ & $8(15.09)$ & 1.481 & 0.678 \\
\hline Unhealthy $(n=130)$ & $45(34.62)$ & $45(34.62)$ & $21(16.15)$ & $19(14.62)$ & & \\
\hline \multicolumn{7}{|l|}{ Exercise } \\
\hline Occasional $(n=49)$ & $16(32.65)$ & $18(36.73)$ & $6(12.24)$ & $9(18.37)$ & 0.885 & 0.829 \\
\hline Regular $(n=134)$ & $48(35.82)$ & $48(35.82)$ & $20(14.93)$ & $18(13.43)$ & & \\
\hline
\end{tabular}

Figures in parentheses represent percentages; $p<0.05$ significant

Table 6: Association of BMI with menorrhagia and oligomenorrhagia

\begin{tabular}{|c|c|c|c|c|c|c|}
\hline & & \multicolumn{3}{|c|}{$B M I$} & \multirow[b]{2}{*}{ Chi-square } & \multirow[b]{2}{*}{$p$ value } \\
\hline \multicolumn{2}{|c|}{ Variables } & Normal & Low & High & & \\
\hline \multirow[t]{2}{*}{ Menorrhagia } & Present $(n=34)$ & $19(55.88)$ & $4(11.76)$ & $11(32.35)$ & 0.182 & 0.911 \\
\hline & Absent $(n=149)$ & $89(59.73)$ & $17(11.41)$ & $43(28.86)$ & & \\
\hline \multirow[t]{2}{*}{ Oligomenorrhea } & Present $(n=27)$ & $22(81.48)$ & $3(11.11)$ & $2(7.41)$ & 7.955 & 0.019 \\
\hline & Absent $(n=156)$ & $86(55.13)$ & $18(11.58)$ & $52(33.33)$ & & \\
\hline
\end{tabular}


In the dietary details, two-third (62.84\%) of the students were vegetarian. It was noted that $71.04 \%$ of students were consuming unhealthy diet, which included fast food, beverages, and sweets at least four to five times per week on a regular basis. Only $28.96 \%$ were having healthy diet, which included salad, fruit, milk, egg, and pulses for at least four to five times per week and they were not on unhealthy diet regularly. Any exercise in the form of walking, going to gym, dance, yoga, or any sports doing four to five times a week for at least 30 minutes was reported by 134 (73.22\%) students in our study. Walking was the commonest followed by going to gym. Out of 134 students who were exercising regularly, $55.97 \%$ complained of dysmenorrhea. Incidence of dysmenorrhea was significantly more $(73.47 \%)$ in girls who were exercising occasionally than in those who were doing exercise routinely $(55.97 \%)$ and this difference was statistically significant $(p=0.032)$. Yesuf et al. had also reported that girls doing regular exercise had less dysmenorrhic pain. ${ }^{3}$ We have seen a lower incidence of dysmenorrhea $(60.66 \%)$ than what is reported by some authors, ${ }^{3-6}$ which is explained by the fact that $73.22 \%$ of our students were involved in one or the other form of regular exercises, which leads to release of endorphins resulting in enhanced pain threshold and hence less incidence of dysmenorrhea. In our study, $90.09 \%$ $(100 / 111)$ of the girls with dysmenorrhea also had one or more symptom of PMS, whereas in students not having dysmenorrhea, PMS was seen in $77.78 \%$ (56/72) of the participants. A strong association was seen between dysmenorrhea and PMS in our study which was statistically significant $(p=0.022)$. In students with severe PMS, 96.15\% (25/26) also had dysmenorrhea and girls with moderate PMS, 65.15\% (43/66), had dysmenorrhea showing a significant association ( $p=0.001)$ between severity of PMS and dysmenorrhea; however, severity of PMS was not significantly correlated with menstrual cycle regularity, BMI, diet, and exercise. Rumana et al. (2017) noted that PMS was more in students with low $\mathrm{BMI}$, those residing in hostels, having vegetarian diet, and with age of menarche less than 10 years. ${ }^{13}$ Rafique and Al-Sheik (2018) found significant correlation between dysmenorrhea, PMS, and stress and also the common symptoms of PMS in their study were mood swings, anger, irritability, and tiredness. ${ }^{6}$ We also observed that there was no significant association of dysmenorrhea with menstrual cycle regularity, BMI, and type of food intake, which is in contrast to the findings of Lakkawar et al. who reported that dysmenorrhea was significantly associated with junk food consumption, low and normal BMI. In their study, high prevalence of PMS was seen in the normal and overweight category and not practicing exercise; also no association was seen between BMI and abnormal flow. ${ }^{4}$ Yesuf et al. (2018) observed a higher incidence of dysmenorrhea (71.8\%) among university health sciences students and found that long menstrual cycle intervals, long menses duration, family history, alcohol, and field of study were associated with it. ${ }^{3}$

We found that out of 27 girls with oligomenorrhea, 22 had normal BMI and a significant correlation $(p=0.019)$ was noted between oligomenorrhea and normal BMI. Menorrhagia was not significantly correlated with BMI ( $p=0.911)$. In our study, no significant correlation was seen between PMS and cycle regularity $(p=0.473), \mathrm{BMI}(p=0.895)$, diet $(p=0.934)$, or exercise $(p=$ 0.405). We observed that physical symptoms of PMS like breast tenderness (39.74\%) and edema (12.02\%) were less as compared to psychological symptoms like mood swings (84.62\%) and food craving (73.72\%) of the students suffering from PMS. The possible explanation could be as $73.22 \%$ students in our study were doing some form of regular physical exercise. Dehnavi et al. have also reported the impact of 8 weeks' aerobic exercise on severity of physical symptoms of PMS and found aerobic exercise as one of the options to alleviate the symptoms of PMS. ${ }^{14}$ High incidence of psychological symptoms of PMS (mood swings, food craving, and headache) seen by us could be because of fluctuating hormonal levels and stress affecting the hypothalamic-pituitary-adrenal axis as also noted by Direkvand-Moghadam et al. ${ }^{15}$

\section{ConClusion}

Menstrual disorders are common among medical students that can affect their psychosocial and physical well-being and are a cause of class absenteeism. In this study, the most common menstrual disorders were PMS, dysmenorrhea, and abnormal uterine bleeding. Common premenstrual symptoms were mood swings, followed by food craving and breast tenderness. Most of our students were consuming unhealthy diet. In our study, a strong association was seen between dysmenorrhea and exercise; students exercising regularly had low incidence of dysmenorrhea. Also significant association of dysmenorrhea was seen with PMS and its severity. Association was noted between oligomenorrhea and normal BMI. Since in our study there was a very high prevalence of PMS with more psychological symptoms, we suggest that future prospective studies may be done to find the personality type, social support system, and stress levels of the students. Timely diagnosis and early management of these menstrual problems can help these medical students to lead a healthy life. It is recommended that physical and emotional health aspects of the students should be addressed with adequate counselling and required treatment so that these students can do justice to their academics and turn out to be healthy clinicians for the community.

\section{Central Trial Registry India (CTRI) Registration}

This trial was registered with CTRI reference number CTRI/2018/05/014059.

\section{Acknowledgments}

We are thankful to Professor S Rudra, Former HOD, Department of Obstetrics and Gynecology, MMIMSR, Mullana, Haryana, for guiding us to do this study.

\section{References}

1. Dutta DC. Textbook of gynecology including contraception Hiralal K, ed., Menstruation, New Delhi: The Health Sciences Publisher; 2016. pp. 66-79.

2. Karki PK, Gupta R. Menstrual pattern. disorders among female students of Kathmandu medical college. Int J Contemp Med Res 2017;4(12):1-3.

3. Yesuf TA, Eshete NA, Sisay EA. Dysmenorrhoea among university health science students, northern ethiopia: impact and associated factors. Int J Reproduct Med 2018;2018:9730328. DOI: 10.1155/2018/ 9730328.

4. Lakkawar NJ, Jayavani RL, Nivedhana AP, et al. A study of menstrual disorders in medical students and its correlation with biological Variables. Sch J App Med Sci 2014;2:3165-3175.

5. Aref N, Rizwan F, Abbas MM. Frequency of different menstrual disorders among female medical students at Taif medical college. World J Med Sci 2015;12:109-114. 
6. Rafique N, Al-Sheik MH. Prevalence of menstrual problems and their association with psychological stress in young female students studying health sciences. Saudi Med J 2018;39(1):67-73. DOI: 10.15537/ smj.2018.1.21438.

7. Fritz MA, Speroff. L. Clinical Gynecologic Endocrinology and Infertility. New York: Lippincott Williams \& Wilkins; 2011. pp. 567-590.

8. Singh R, Sharma R, Rajani H. Impact of stress on menstrual cycle: a comparison between medical and non medical students. Saudi J Health Sci 2015;4(2):115-119. DOI: 10.4103/2278-0521. 157886.

9. Mohite RV, Mohite VR. Correlates of the menstrual problems among rural college students of Satara district. Al Ameen J Med Sci 2013;6(3):213-218.

10. Ansong E, Arhin SK, Cai Y, et al. Menstrual characteristics, disorders and associated risk factors among female international students in Zhejiang Province, China: a cross-sectional survey. BMC Women's Health 2019;19(1):35. DOI: 10.1186/s12905-0190730-5.
11. Karanth S, Liya SR. Prevalence and risk factors for dysmenorrhoea among nursing student and its impact on their quality of life. Int J Reprod Contracept Obstet Gynecol 2018;7(7):2661-2667. DOI: 10.18203/2320-1770.ijrcog20182483.

12. Teshome SM, Wubshet M, Tegabu D. Menstrual problems and associated factors among students of Bahir Dar university, Amhara National Regional State, Ethiopia: a cross-sectional survey. Pan Afr Med J 2014;17:246. DOI: 10.11604/pamj.2014.17.246.2230.

13. Rumana Akbari M, Sudharani M, Kallupurackal SJX, et al. Prevalence of premenstrual syndrome among medical students. National J Commun Med 2017;8(6):292-294.

14. Dehnavi ZM, Jafarnejad F, Goghary SS. The effect of 8 weeks aerobic exercise on severity of physical symptoms of premenstrual syndrome: a clinical trial study. BMC Womens Health 2018;18(1):80. DOI: 10.1186/ s12905-018-0565-5.

15. Direkvand-Moghadam A, Ali Delpisheh KS, Kaikhavandi S. Epidemiology of premenstrual syndrome (PMS)-A systematic review and meta-analysis study. J Clin Diagnos Res 2014;8(2):106-109. 